\title{
An Eco-Efficient Helicopter Tailplane Hybridized from Flax, Balsa and Carbon
}

\author{
K. Strohrmann* and M. Hajek ${ }^{\dagger}$ \\ Institute of Helicopter Technology, Technical University of Munich, Boltzmannstr 15, Garching, Germany
}

\begin{abstract}
A tailplane for an ultralight helicopter was redesigned with the goal of using bio-based materials in a high proportion. Structural requirements were set to the national ultralight certification standards and were also adapted from the performance of the initial design tailplane, which was made of carbon prepreg materials and a foam core. In order to pursue this goal, pre-impregnated flax fiber composites, in combination with a balsa wood core and a small proportion of carbon fiber reinforcements, were used to design a new tailplane.

A finite element model was developed, fed by material data from tensile tests and evolving iteratively from coupon and sub-component bending tests. Finally, a $450 \mathrm{~mm}$ section of the resulting design was built and a bio-based mass content of approximately $55 \%$ was achieved. The new, hybrid version was analyzed experimentally in terms of weight, stiffness, strength/ failure, damping, and embodied energy, where benchmark data was obtained from either the reference tailplane or the certification specifications. Benefits of the new design were identified in a 2-8 times higher damping ratio, 65\% less embodied energy $\left(76.90 \mathrm{MJ} \mathrm{kg}^{-1}\right)$, and reduced carbon footprint $\left(5 \mathrm{~kg} \mathrm{~kg}^{-1}\right)$, while weight, stiffness, and strength were performing in a sufficient and comparative manner as the reference.
\end{abstract}

\section{Nomenclature}

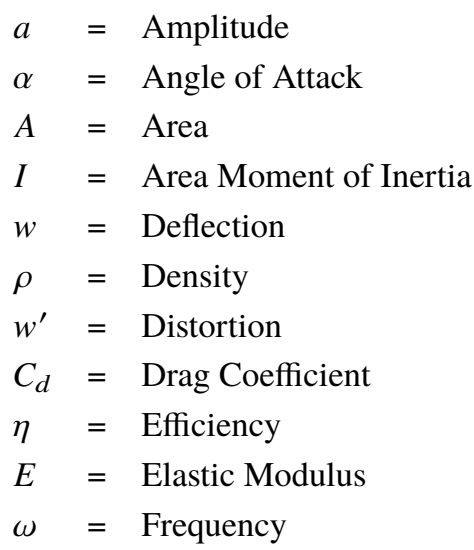

$\begin{array}{ll}C_{l} & =\text { Lift Coefficient } \\ \Phi & =\text { Mode Shape Vector } \\ M & =\text { Moment } \\ C_{m} & =\text { Moment Coefficient } \\ v_{N E} & =\text { Never Exceed Velocity } \\ v & =\text { Poisson's Ratio } \\ p & =\text { Pressure } \\ C_{p} & =\text { Pressure Coefficient } \\ S_{F} & =\text { Safety Factor } \\ G & =\text { Shear Modulus }\end{array}$

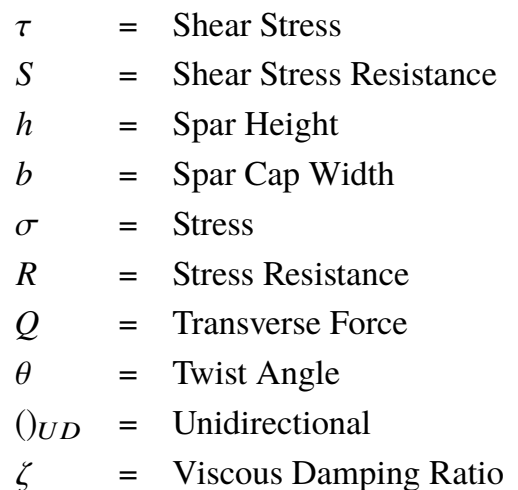

\section{Introduction}

The goal of using natural materials is to improve the eco-efficiency of structural parts. The main aspect hereby can be substantiated by the significantly lower energy input in the production process [1]. Also, the carbon footprint and recyclability are beneficial aspects with the use of flax composites instead of carbon composites. The flax-fiber reinforced material in this application shows excellent damping properties combined with a strength $\left(R_{U D}=275 \mathrm{MPa}\right)$ comparable to conventional metallic materials and an initial stiffness of more than $E_{U D}=30 \mathrm{GPa}$, comparable to GFRP.

The aim of this work is to demonstrate the potential of natural fiber-reinforced polymers (NFRP) in helicopter structural applications. The platform designated for this endeavor was the horizontal tailplane of an ultralight helicopter, the CoAX

\footnotetext{
*Graduate Student, Technical University of Munich, Boltzmannstr 15, Garching, Germany

${ }^{\dagger}$ Professor and Department Head,Technical University of Munich, Boltzmannstr 15, Garching, Germany
} 
2D by edm aerotec $\mathrm{GmbH}$.

A section of this tailplane was built as structural demonstrator. It has a span of $0.45 \mathrm{~m}$ and a chord of $0.25 \mathrm{~m}$, where the prior design with a solid core and carbon woven skin was adapted in the airfoil geometry. The span of the reference tailplane was significantly shorter than the span of the new design; both will be compared by the same section length. The prior design will serve as reference in dynamic and environmental performance, while strength, stiffness and structural demands will be calculated from the maximum aerodynamic loads and an additional vertical gust, as calculated using a panel method.

State-of-the-art helicopter tailplanes are likely to be made out of metallic or carbon fiber-reinforced materials, with typically no ambition in eco-efficient material use. Nevertheless, conventional tailplanes are optimized in terms of weight, which results in energy savings in the operational life. In order to show proportionality of production and operational life, the ultralight helicopter of this application is analyzed in terms of embodied energy.

Considering $50 \mathrm{~kg}$ CFRP structural cabin mass in the $450 \mathrm{~kg}$ MTOW ultralight helicopter, whereas carbon fiber consumes $380-420 \mathrm{MJ} \mathrm{kg}^{-1}$ and flax as natural fiber only consumes $10-12 \mathrm{MJ} \mathrm{kg}^{-1}$ in primary production [2], and a fiber mass fraction of $60 \%$ is provided, we conclude an energy saving potential of $11.7 \mathrm{GJ}$. Furthermore, we consider a typical power-to-weight ratio of $0.20 \mathrm{~kW} \mathrm{~kg}^{-1}$ in helicopters, which results in an energy penalty of $1.44 \mathrm{MJ}(\mathrm{kg} \mathrm{h})^{-1}$ when an efficiency of $\eta=0.4$ and an average used power of $80 \%$ of the maximum power is considered. In summary, with an assumed life-cycle of 10,000 h, the break even in terms of embodied energy is reached when the hybrid cabin is $2.7 \%$ heavier than the reference. Eventually, the high energy demand in the operational life strongly influences the overall eco-efficiency, but minor drawbacks in weight, between $1-2 \%$ was still be able to increase the overall eco-efficiency when significant reductions in the embodied energy of the primary production can be achieved.

Furthermore, the costs for flax are 2.1-4.20 USD kg-1 while carbon fiber costs 124-166 USD kg-1, these prices are given in [2] and are ascertained for the raw fiber. Considering processed prepreg materials with epoxy coating, the prices will converge, but a remaining, significant benefit is expected.

Another beneficial aspect should be addressed. Helicopter tail shake or other uncomfortable vibrations are a common but undesired phenomenon, likely to be induced by an aerodynamic excitation of impulsive character. The high damping ratios of NFRP (up to 5-10 times higher than CFRP [3, 4]) are considered technically beneficial in this application.

\section{Design and Methodology}

First, the design load case was defined by the aerodynamic load at the helicopter' maximum speed, maximum angle of attack, and an additional vertical gust of $10 \mathrm{~m} \mathrm{~s}^{-1}$ as defined in the certification specifications. The aerodynamic load was calculated using a panel method and the tool Xflr5, resulting in a total down-thrust of about $1.10 \mathrm{kN}$ as safe load and, regarding a safety margin of 1.875 , an ultimate load of approx. $2 \mathrm{kN}$ was determined.

The vertical gust was increasing the angle of attack to a value where laminar flow would separate, but assuming a dynamic gust and considering a conservative design, the load was still taken into account. Xflr5 uses a linearized model of the $C_{L}-\alpha$ relation, therefore a separation was not included in the model and viscous drag was also neglected.

The results of $C_{p}$-distribution over the tailplane are shown in Fig. 11 The input data was compared to flight test data and represent conservative values [5]. Fig. 1] also shows the lift vectors, in green, normal on the panels. The lift vectors per span-section were used for the preliminary design.

The preliminary design examined different structural concepts, as a result, wings with respective chord length are typically more lightweight with a spar design than the ones with a core design. Then the spar was designed to bear bending loads, while skin and web were designed to withstand shear loads. The spar material and necessary thickness was determined by calculating the iteratively summarized moments resulting from transverse forces on the panels. See equation (1).

$$
M_{i, y}=S_{F} \cdot \sum_{1}^{n} \frac{\rho}{2} \cdot v_{N E}^{2} \cdot\left(\cos (\alpha) \cdot c_{l, i}+\sin (\alpha) \cdot c_{d, i}\right) \cdot a_{i} \cdot x_{i}
$$



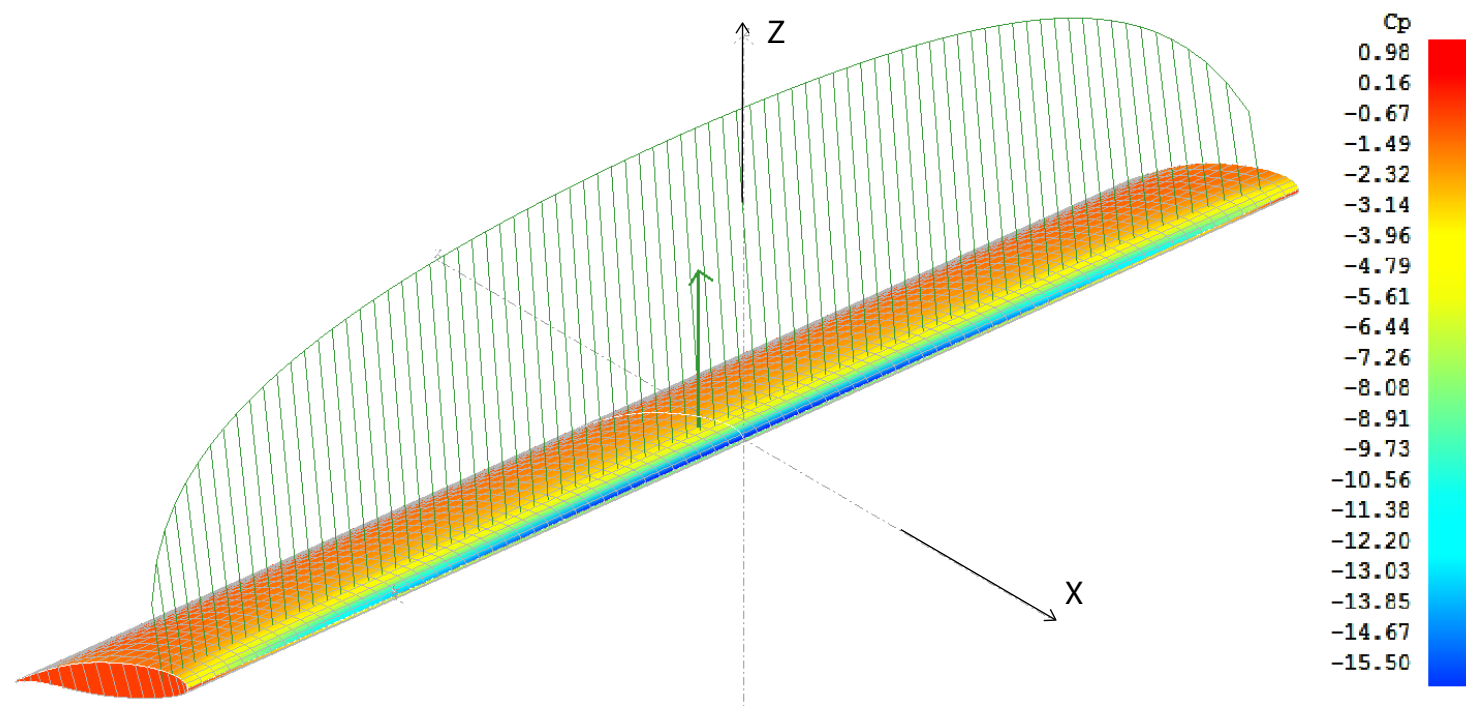

Fig. 1 Pressure coefficient plot $C_{p}$ on the tailplane surface (colored) and lift vectors per span-wise sections (green).

The resulting moment was then concluding to the bending stiffness and inertia needed, see equation (2). Considering the maximum allowed deformation of $w_{\max }=10 \mathrm{~mm}$ and the calculations as in equations (3) and (4), it turned out that CFRP layers would be needed for the spar caps due to its inherent stiffness.

$$
\begin{gathered}
I_{i, y}=\sum_{1}^{n} \frac{M_{i, y} \cdot z_{\text {max }}}{\sigma_{i}} \\
w_{i}^{\prime}=\frac{M_{i, y} \cdot \Delta x}{E \cdot I_{y}}+w_{i-1}^{\prime} \\
w_{i}=\frac{M_{i, y} \cdot x^{2}}{2 \cdot E \cdot I_{y}}+w_{i-1}^{\prime} \cdot \Delta x+w_{i-1}
\end{gathered}
$$

Next, the shear forces in the spar web were summarized as three components, shear due to transverse force (I), shear due to spar cap downward forces (II), and shear due to elastic deformation of the upper and lower spar caps (III). Because the components (II) and (III) were very small, the only component considered in the preliminary design was (I), shear due to transversal load, which was iteratively summarized for each span panel. See equation (5).

$$
\tau_{i}=\tau_{(I), i}+\tau_{(I I), i}+\tau_{(I I I), i} \approx \sum_{1}^{n} \frac{Q_{i} \cdot\left(a_{c a p s} \cdot z_{c a p s}+a_{w e b} \cdot z_{w e b}\right)}{I_{y y} \cdot t_{w e b}}
$$

In the next step, the airfoil skin was designed to bear the torsional loads, which were calculated in equation (6). Additionally, the stiffness was designed under the constraint $\theta_{\max }<10^{\circ}$, and calculated in equation (7).

$$
\begin{gathered}
M_{i, x}=S_{F} \cdot \sum_{1}^{n} \frac{\rho}{2} \cdot v_{N E}^{2} \cdot c_{m, i} \\
\theta_{i}=\frac{M_{i, x} \cdot \Delta x}{G_{x y} \cdot I_{t}}+\theta_{i-1}
\end{gathered}
$$

All in all, a hybrid design with CFRP spar caps for bending loads and flax skins and spar web taking shear loads was evaluated as the most suitable for this application, regarding the goals of a high bio-based mass content and fulfillment of mechanical constraints.

The preliminary design from above-described analytical results was modeled with the FEA tool Ansys and its composite environment. The calculated pressure distribution of the panel method (see Figure 1) was imported to the model. 
Therefore, the $C_{p}$ data was transformed into pressure values with equation (8), which were mapped on the FEA mesh, using a triangulation algorithm. An acceptable mapping error of less than $1 \%$ was determined.

$$
p_{i}=c_{p, i} \cdot \frac{1}{2} \cdot \rho_{\infty} \cdot v_{N E}^{2}\left(+p_{\infty}\right)
$$

As no air tightness was assumed, $p_{\infty}$ would load inside and outside surfaces in the same manner and the resulting forces and moments would even out, thus $p_{\infty}$ was neglected.

Next, the strength and stiffness requirements were analyzed in the FEA model with a variation of lay-ups and materials. A critical design requirement using flax was determined from tensile tests [6-8], which showed that flax fibers deform non-linearly under tensile load, especially cross-ply laminates. As the safe load should be bearable without plastic deformation, which is the beginning non-linear behavior was implemented by the identified "yield" points and the Hashin criterion, described in more detail in [6]. Whereas the ultimate load is allowed to cause plastic deformation, the maximum strain criterion was therefore applied for this demand.

The described methodology was concluded to the final design, which is shown in Fig. 2. The flax skins and spar web were designed as sandwich with an additional $2 \mathrm{~mm}$ balsa core in the symmetry plane in order to prevent buckling. The table lists the used materials with respective fiber orientation angles in the suffix. The abbreviation $F$ stands for unidirectionally flax fiber reinforced layers with a thickness of $0.16 \mathrm{~mm}$. The letter $B$ indicates a $2 \mathrm{~mm}$ layer of balsa wood, $C$ represents CFRP with a $0.58 \mathrm{~mm}$ thickness, also unidirectionally reinforced. And $G$ stands for a glue (Scotch-Weld ${ }^{\mathrm{TM}}$ 9323), which was used to assemble shear web and airfoil skin. The thickness was approximated by $0.50 \mathrm{~mm}$ but variates between 0.1 and $1 \mathrm{~mm}$. All materials are also listed with their mass-percentage in Table 4 . The position of the span is defined at the shear center of the skin, $\mathrm{x}=110 \mathrm{~mm}$ in aerodynamic coordinates, which was also the position of $X_{C P}$ at a $0^{\circ}$-angle of attack. The authors are well aware that the $X_{C P}$ location is moving closer to the leading edge with increasing angles of attack, this position was still considered profitable in order to suppress complex shear-bending couplings.

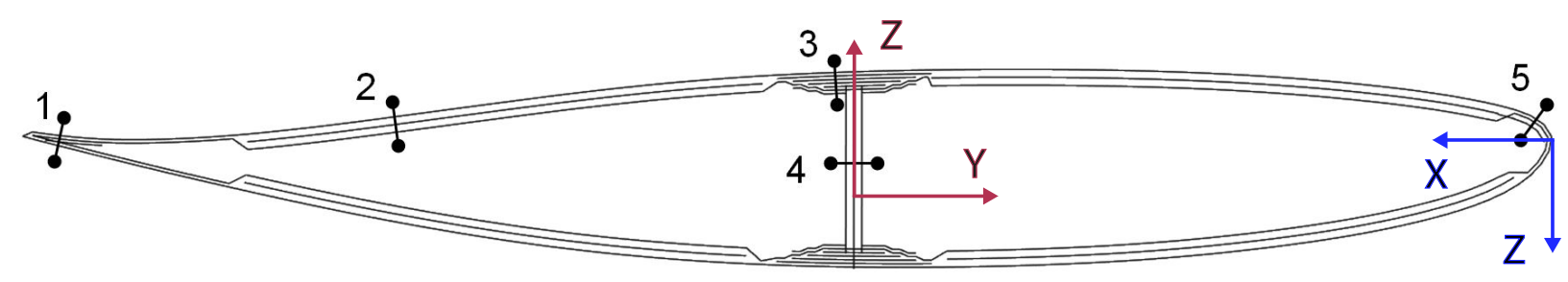

Sampling Point $\quad$ Stack-Up

$\begin{array}{cl}\mathbf{1} & {\left[F_{+45} / F_{-45} / F_{+45} / F_{-45} / F_{0} / F_{0} / F_{0} / F_{-45} / F_{+45} / F_{-45} / F_{+45}\right]} \\ \mathbf{2} \text { and } 4 & {\left[F_{+45} / F_{-45} / F_{+45} / F_{-45} / B_{0} / F_{-45} / F_{+45} / F_{-45} / F_{+45}\right]} \\ \mathbf{3} & {\left[F_{+45} / F_{-45} / F_{+45} / F_{-45} / C_{0} / C_{0} / C_{0} / C_{0} / F_{-45} / F_{+45} / F_{-45} / F_{+45} / G / F_{-45} / F_{+45} / F_{+45} / F_{-45}\right]} \\ \mathbf{5} & {\left[F_{+45} / F_{-45} / F_{+45} / F_{-45} / F_{+45} / F_{-45} / F_{+45} / F_{-45} / F_{-45} / F_{+45} / F_{-45} / F_{+45}\right]}\end{array}$

Fig. 2 Tail plane section cut and material stack-ups at various sampling points with aerodynamic coordinate system (blue) and measurement coordinate system (red)

The analytical and numerical results of the design were validated and iteratively supported by experimental tests. Firstly, the plain flax and plain carbon material was characterized with tensile tests of $0^{\circ}, 90^{\circ}$, and $\pm 45^{\circ}$ laminates using the DIC method ARAMIS [6]. Next, the sandwich lay-up of $\left[ \pm 45_{F, 4} / 0_{B}\right]_{S}$ was validated in a flexural test, as well as the whole carbon-flax-balsa spar. Finally, a $450 \mathrm{~mm}$ section of the tailplane was built from two components. The airfoil section was built in one step, using an inner tube to apply the vacuum. The second component, the shear web, was made from flax with a balsa core. Both components were glued together with the two-component glue Scotch-Weld ${ }^{\mathrm{TM}} 9323$. 


\section{Experimental Results}

As goal of this work, the structural performance of the partly bio-based tailplane was analyzed experimentally regarding the demands of certification specifications for ultralight helicopters. Furthermore, the mechanical feasibility of a lightweight structural part made of biocomposites were proven and potentials in damping performance were quantified. The experimental results include quasi-static tests where stiffness and strength of the new hybrid design were analyzed and an experimental modal analysis (EMA) was performed in order to prove accordance to the FEA model and to determine damping ratios. Static tests and the EMA were modeled numerically, results were compared and verified.

\section{A. Static Tests on Elasticity and Failure}

First, tensile tests covered the verification of composite material characteristics from respective data sheets, where unidirectionally carbon and flax reinforced coupons were tested in the following fiber angle orientations: $0^{\circ}, 90^{\circ}$, and $\pm 45^{\circ}$. Missing characteristics, such as shear and poisson's ratio in transversal direction were estimated from conventional laminates. A detailed description of the flax tensile tests is published in [6], including a bilinear modeling approach. A summary of the flax composite's elastic properties is listed in Table 1 , strength and strain properties are listed in Table 2 .

Table 1 Elasticity values of flax laminate tensile tests

\begin{tabular}{lcc}
\hline Parameter & Unit & Value \\
\hline$E_{1}$ & {$[\mathrm{GPa}]$} & 31.99 \\
$E_{2}=E_{3}$ & {$[\mathrm{GPa}]$} & 2.21 \\
$v_{12}=v_{13}$ & {$[-]$} & 0.37 \\
$v_{23}$ & {$[-]$} & 0.08 \\
$G_{12}=G_{13}$ & {$[\mathrm{GPa}]$} & 1.38 \\
$G_{23}$ & {$[\mathrm{GPa}]$} & 1.07 \\
\hline
\end{tabular}

Table 2 Ultimate stresses and ultimate strains of flax laminate tensile tests

\begin{tabular}{lcr}
\hline Parameter & Unit & Value \\
\hline$R_{1}$ & {$[\mathrm{MPa}]$} & 274.50 \\
$R_{2}=R_{3}$ & {$[\mathrm{MPa}]$} & 3.87 \\
$S_{12}=S_{13}$ & {$[\mathrm{MPa}]$} & 24.67 \\
$S_{23}$ & {$[\mathrm{MPa}]$} & 24.67 \\
$\epsilon_{1, \max }$ & {$[\%]$} & 1.28 \\
$\epsilon_{2, \max }=\epsilon_{3, \max }$ & {$[\%]$} & 0.20 \\
\hline
\end{tabular}

Next, using the material model of the flax laminates, the lay-up of the flax-balsa sandwich sections, with the same lay-up as position 2 and 4 of Fig. 2 were tested in a 4-point bending test. In comparison to the FEA model, it was shown that the general elastic behavior was modeled well, whereas the scatter between different specimens was higher than the deviation between measurement and model see Fig. 3 .

In order to identify failure of the sandwich laminates the Hashin criterion, "core failure," and the maximum strain criterion were applied. In the experiments, all sandwich beams were failing in a shear fracture mode of the balsa wood core. This was predicted at the right position (between load initiation positions) by the FEA model, besides tensile matrix failure. Fig. 4 shows the applied failure criteria at the break load of $180 \mathrm{~N}$ from the experimental tests. The FEA shows tensile matrix failure with an inverse reverse factor of 1.20 and core failure with an inverse reserve factor of 1.45. As a conclusion, failure was predicted at the right position and in the right mode, but specimens in the experiment withstood failure up to higher loads than the model predicted. This underestimation was accepted, because failure should rather be predicted too early in design due to security aspects.

The Hashin criterion was also analyzed in terms of the "yield" point of the material, and showed tensile matrix failure starting right above $100 \mathrm{~N}$. As the stress resistance values used in the Hashin approach were defined at where the cross-ply laminates in the tensile tests diverged from the linear model, this failure criterion marks the initiation of non-linear behavior (detailed explanation in [6]). Thus, a resulting stiffness reduction of the specimens above $100 \mathrm{~N}$ was expected, which was only observable in one of the three specimens, see Fig. 3

Similar analysis was done on failure behavior of the whole beam section of the tailplane, but will not be discussed in detail in order to avoid redundancy. This beam section was tested in a 3-point bending test; failure occurred in the spar flanges right at the load initiation in the middle of the beam. 


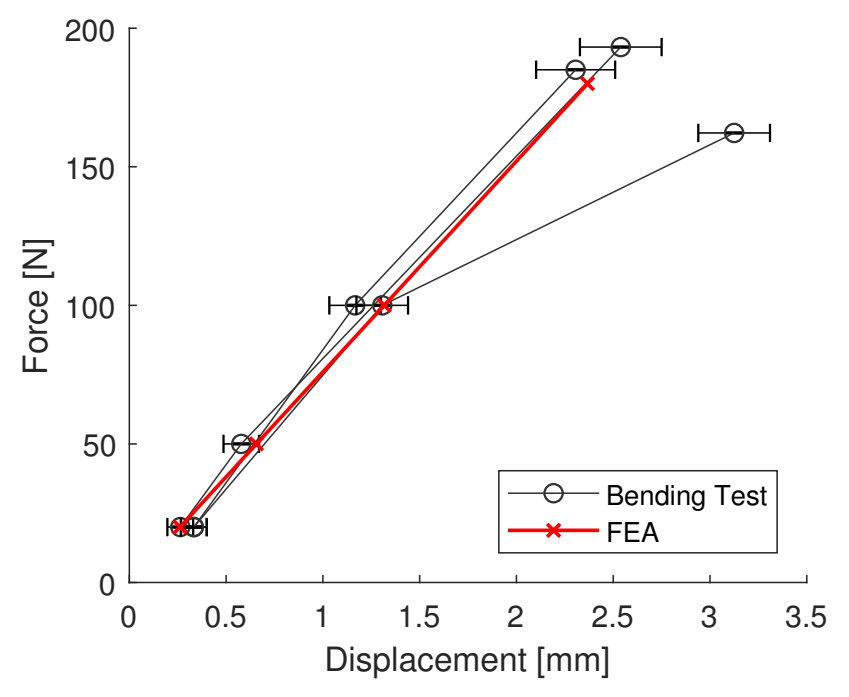

Fig. 3 Verification of stiffness model with three flax-balsa sandwich coupons with the lay-up as in sampling point 2 and 4 of Fig. 2

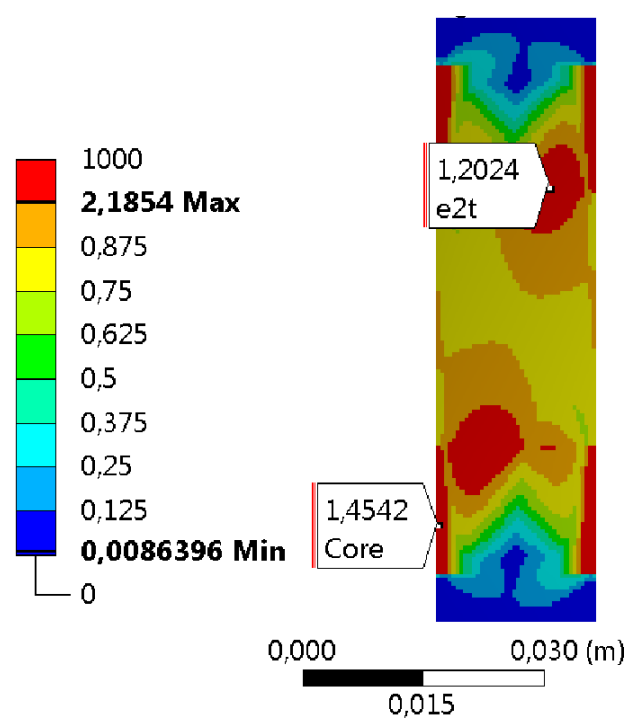

Fig. 4 Inverse reverse factor of FEA using core failure and max. strain criterion

Concluding from the pre-tests, a section of $450 \mathrm{~mm}$ of the final tailplane design was built. The ultralight certification standards define that under the safe load there is no plastic deformation allowed. Therefore, the Hashin failure criterion, using the "yield" stresses as described above, was applied to the design. The ultimate load is defined with plastic deformation allowed, whereas rupture or complete failure is not. In order to fulfill the constraints of the ultimate loads, the maximum strain criterion, using values from the tensile tests as in Table 2, were applied. The FEA calculations showed that the elasticity constraint at the safe load is the more delicate constraint, thus the following focuses on verification of the safe load.

The safe load was defined by the maximum aerodynamic load from the initially described calculation, where in the following only one half-span is examined and thus, the loads reduce from $1.10 \mathrm{kN}$ safe load and $2 \mathrm{kN}$ ultimate load to $0.55 \mathrm{kN}$ safe load and $1 \mathrm{kN}$ ultimate load respectively. The center of lift of the aerodynamic cp-distribution was adapted to the experimental set-up, where, combined with a load initiation angle of $18.7^{\circ}$, the load vector equals the summarized panel forces from the aerodynamic load. Additionally, the clamping reaction moments were adapted from the aerodynamic load calculation. Table 3 gives a summary of the reaction forces and moments, which resulted from the aerodynamic load and the experimental setup. Coordinates are as shown red in Fig. 2 and $x=0$ is defined at the beginning of free "cantilever beam."

Fig. 5 shows a photograph of the experimental setup of the static load tests. The reflecting marks are used for photogrammetry measurements.

Table 3 Boundary reaction forces and moments of aerodynamic panel loads and experimental set-up, both from FEA

\begin{tabular}{lc|ccc|c} 
Load & Unit & $\mathrm{X}$ & $\mathrm{Y}$ & $\mathrm{Z}$ & Total \\
\hline Coordinates of Load Initiation & {$[\mathrm{mm}]$} & 288 & 36 & 20 & - \\
\hline Aerodynamic Pressure Distribution & {$[\mathrm{N}]$} & 0 & 531.3 & -173.5 & 559.0 \\
Experimental Setup & {$[\mathrm{N}]$} & 0 & 532.0 & -174.0 & 559.7 \\
Deviation & {$[\%]$} & 0 & 0.13 & 0.29 & 0.13 \\
\hline Aerodynamic Pressure Distribution & {$[\mathrm{Nm}]$} & -28.1 & -47.7 & -153.2 & 162.9 \\
Experimental Setup & {$[\mathrm{Nm}]$} & -30.1 & -54.5 & -166.5 & 177.8 \\
Deviation & {$[\%]$} & 7.12 & 14.26 & 8.68 & 9.14 \\
\hline
\end{tabular}




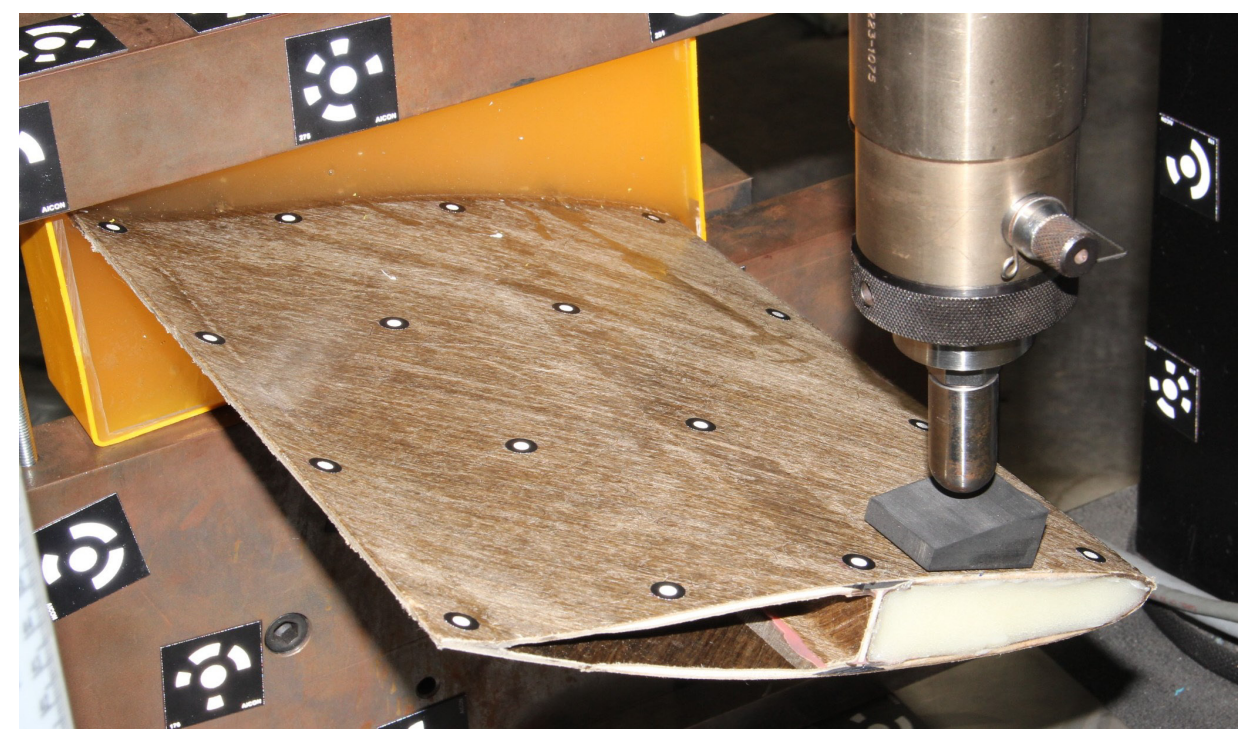

Fig. 5 Experimental setup of cyclic loading in a cantilever beam with force application angle of $18.7^{\circ}$

The cantilever setup of the experiment was done by embedding a $50 \mathrm{~mm}$ section in epoxy, which was then clamped in a steel frame, see Fig. 5. The reference coordinate system for the photogrammetric measurement was applied to the steel frame in order to diminish global deformations. At the point of load initiation, the tailplane was filled with epoxy in a section of $30 \mathrm{~mm}$ depth. Without the epoxy reinforcement, the skin would have failed locally at the load initiation, which would not be the case for the evenly distributed aerodynamic load, and therefore, should be avoided.

Experimental results satisfied the maximum load design, which aimed for an ultimate load of $1 \mathrm{kN}$ or. $288 \mathrm{Nm}$, and the peak load of the experiment was $2510 \mathrm{~N}$ or. $715 \mathrm{Nm}$. The failure showed buckling on the bottom side of the tailplane and was not considered catastrophic failure. A plastic deformation with a maximum value of $0.28 \mathrm{~mm}$ was measured after the ultimate load release. Therefore, the non-linear behavior of the cross-ply laminate resulted in a permanent deformation, but not a significant deflection. The deformation after the safe load release was smaller than $0.10 \mathrm{~mm}$ and did not consecutively increase following the next load steps, thus it was considered an elastic deformation without failure, and the safe load criterion was met as well in terms of the specifications.

The comparison of experimental results with FEA was done by the 3D-displacement vectors at each point of photogrammetric measurement. The view in X-direction is shown in Fig. 6a). It can be seen that the length of the deformation vectors and its angles fit well with the calculated values.

Additionally, the points along the spar were analyzed as a beam approximation. Fig. 6b) shows the deformation at the safe load and ultimate load as well as the deformation after release of the loads where the indications mean: 1 after safe load and 2 after ultimate load. The deformation under the safe load shows good agreement with the FEA results, while the model predicts too small deformations at the ultimate load. As the design is accepting non-linear behavior after the safe load, this would be a cause for the underestimation of the linear material model. The slightly deformed unloaded shape ( 2 in Fig. 6b) ) is supporting this assumption. Additionally, the first measurement point, close to the epoxy embedded clamping, is deflecting highly, therefore a measurement error due to clamping deformations could also account for this discrepancy.

Failure was predicted at lower loads than measured in the experiment. Thus, all certification criteria were met, and there might still be weight reductions possible. The limiting factor for the design was the beginning of non-linear deformation of the cross-ply laminates, where permanent deformation was expected and was observed in the experiments in a small proportion. Therefore, the ultimate load (1.875 times the safe load) was not the maximum bearable load by design. 


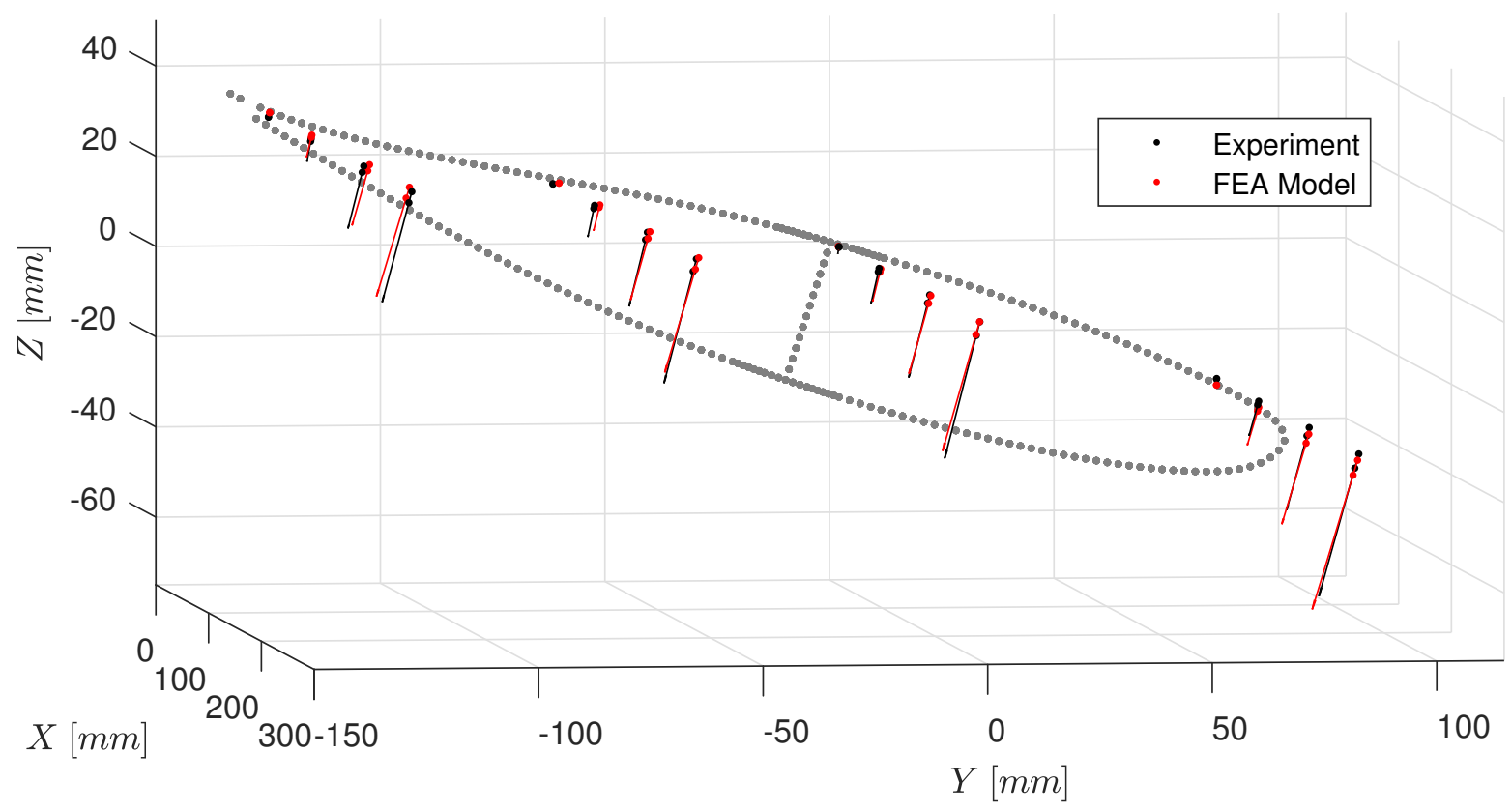

a)

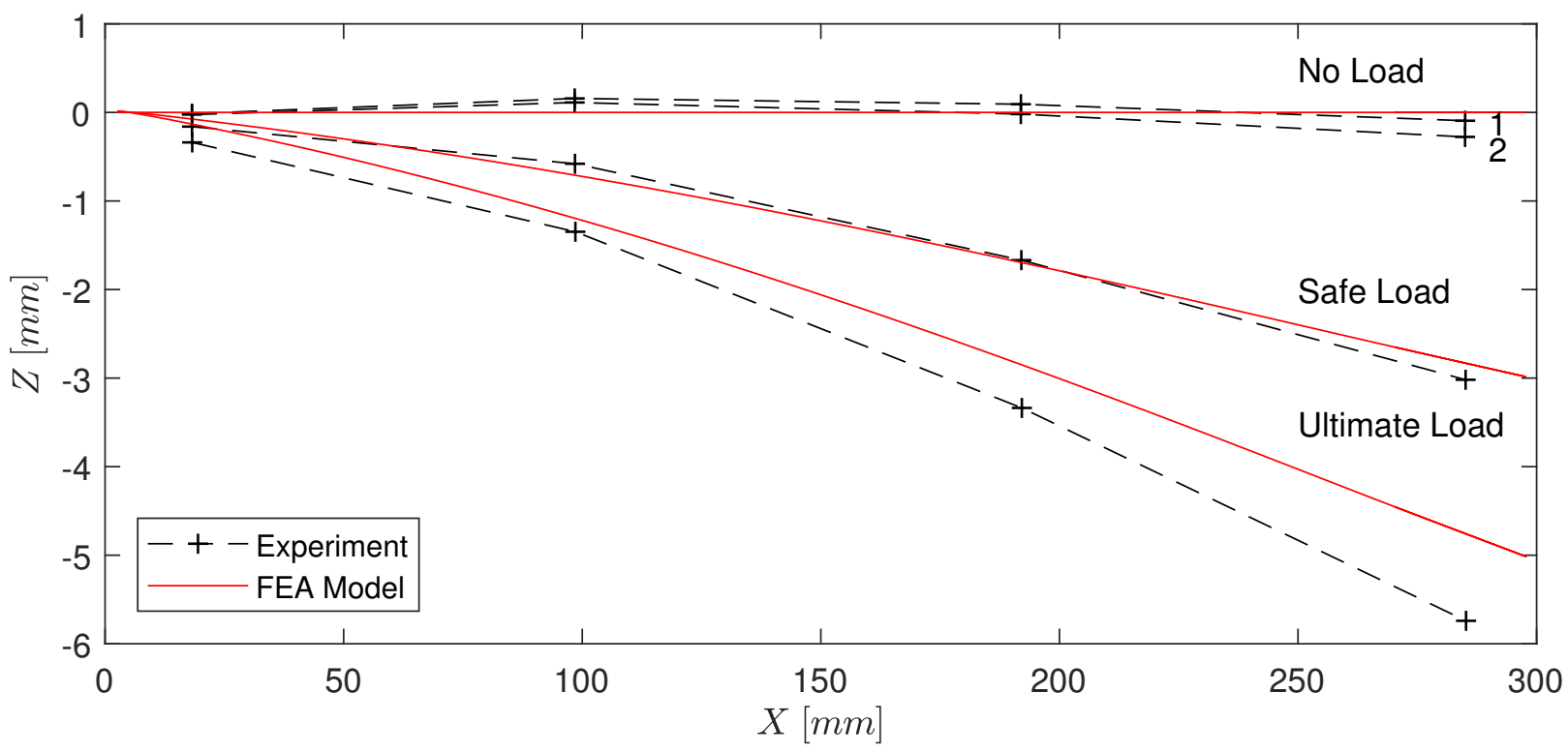

b)

Fig. 6 Experiment and FEA deformation of quasi-static loading, a) 3D plot of deformation vectors at safe load, b) points at spar position of the tailplane in $X-Z$ plane with no load (1 —after safe load, 2 —after ultimate load), safe load, and ultimate load 


\section{B. Experimental Modal Analysis}

According to literature, flax and other natural fiber reinforced structures (NFRP) show very high damping ratios compared to conventional CFRP structures [9-11]. To find out about the damping performance of the hybrid design tailplane, a free-free configuration EMA was performed on both, the reference CFRP tailplane and the hybrid NFRP tailplane. The results were compared in terms of swing-out behavior and frequency response, see Fig. 77. It can be seen that the logarithmic decrement of the hybrid tailplane is higher, and the frequency response of the hybrid tailplane is blunter at resonance frequencies compared to the carbon reference.

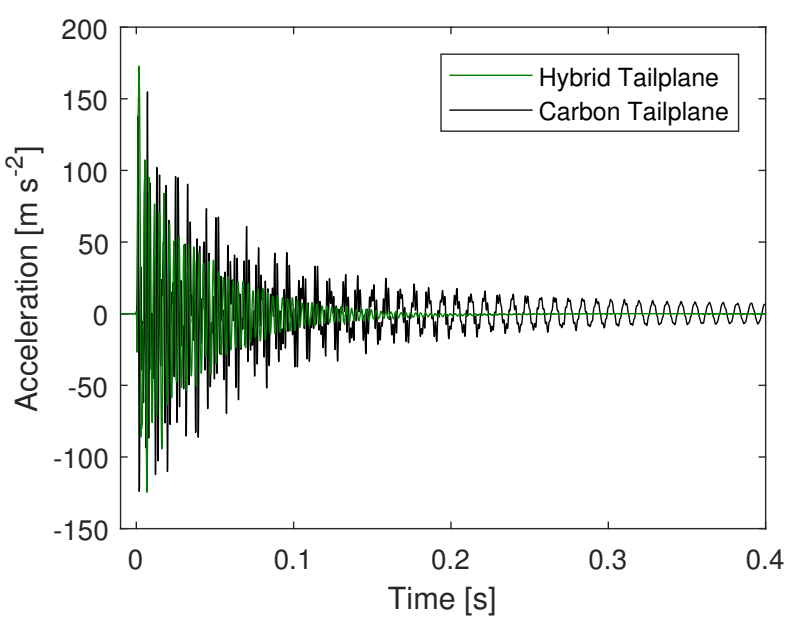

a)

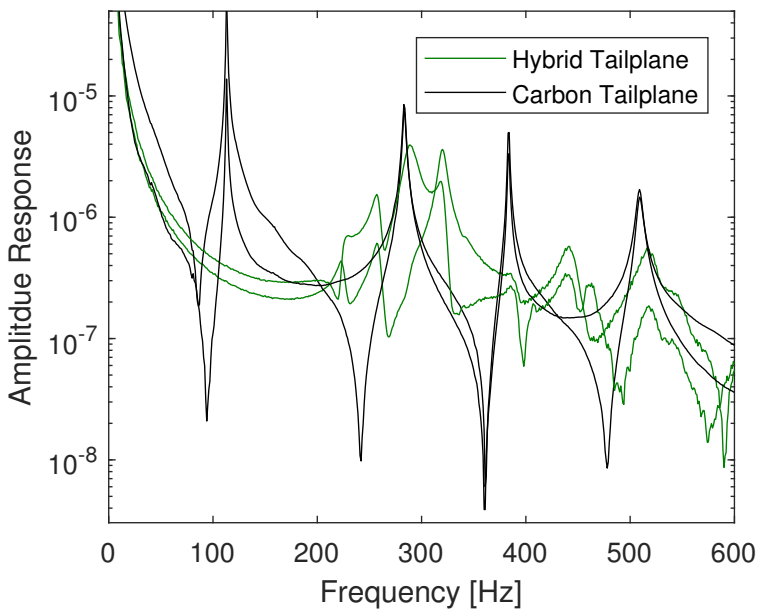

b)

Fig. 7 Comparison of hybrid tailplane and carbon tailplane in terms of logarithmic decrement in a) as acceleration over time, and frequency response in $b$ )

In order to quantify the better damping of the new design tailplane, the frequency dependent damping ratios were determined using the half-power-bandwidth method, results are shown in Fig. 9 The damping ratio $\zeta$ is defined in equation 9 , where $\omega_{n}$ is the respective eigenfrequency and $\omega_{1}$ and $\omega_{2}$ are defined by the frequency response function at the position of $2^{-\frac{1}{2}} a$, with $a$ as maximum amplitude response of the eigenfrequency. This method is based on ASTM Standard E756 [12].

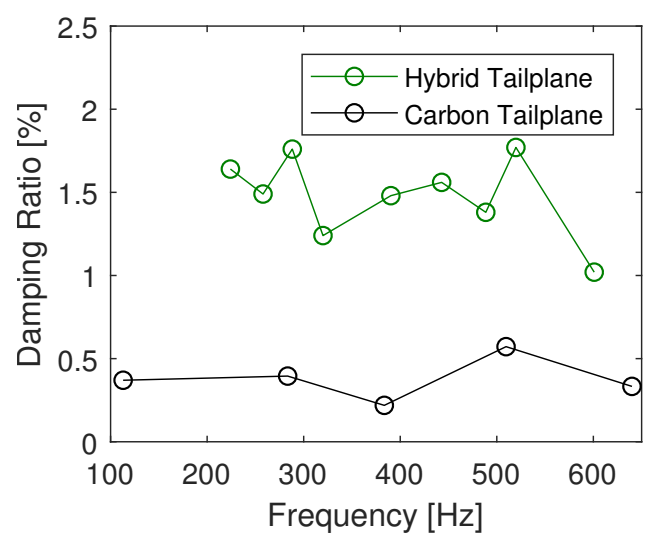

a)

\begin{tabular}{lcc}
\multicolumn{3}{c}{ Carbon Tailplane } \\
\hline Mode & $\mathrm{f}[\mathrm{Hz}]$ & $\zeta$ \\
\hline 1. & 113.0 & 0.00370 \\
2. & 283.4 & 0.00395 \\
3. & 383.5 & 0.00219 \\
4. & 509.6 & 0.00572 \\
5. & 640.0 & 0.00333 \\
\hline
\end{tabular}

b)

\begin{tabular}{lcc}
\multicolumn{3}{c}{ Hybrid Tailplane } \\
\hline Mode & $\mathrm{f}[\mathrm{Hz}]$ & $\zeta$ \\
\hline 1. & 224.1 & 0.0164 \\
2. & 257.9 & 0.0149 \\
3. & 288.2 & 0.0176 \\
4. & 320.0 & 0.0124 \\
5. & 390.3 & 0.0148 \\
6. & 442.9 & 0.0156 \\
8. & 488.6 & 0.0138 \\
9. & 600.9 & 0.0102 \\
\hline
\end{tabular}

c)

Fig. 8 Comparison of damping ratios in diagram a) and tabular values of carbon tailplane in b) and hybrid tailplane in c) 


$$
\zeta=\frac{\omega_{2}-\omega_{1}}{2 \omega_{n}}
$$

The viscous damping ratios of the carbon tailplane were between $0.22 \%$ and $0.57 \%$, while the new hybrid design was damped with ratios between $1.0 \%$ and $1.8 \%$. This results in approximately two to eight times higher damping ratios in the new design. Still, structural damping is only one part of the damping mechanisms in helicopters, besides frictional, aerodynamic, and viscous damping. But in terms of cabin vibration and noise reduction, NFRP offer great potential. Fig. 9 shows the frequencies of the experimental modal analysis versus the resonance frequencies from the FEA calculations. Modes 1-3 and 5 show good agreement, but were higher in the FEA model, while the 4th mode is off by approximately 17\%; modes 7-9 are in a range between 6 and $8 \%$ too low in the FEA calculations. In order to find out about the proper allocation of frequencies, the mode shapes were compared via the Modal Assurance Criterion (MAC). The criterion uses the normalized vectors of the mode shapes and compares the direction. Identical vectors result in a MAC value of 1 , perpendicular vectors result in a MAC value of 0 . The MAC values are calculated by eq. (10), with $\Phi_{i}$ accounting for the mode shape vectors. The results of the comparison of the first five mode shapes are plotted in a matrix in Fig. 9

$$
M A C=\frac{\left|\Phi_{1} \cdot \Phi_{2}\right|^{2}}{\left|\Phi_{1} \cdot \Phi_{1}\right| \cdot\left|\Phi_{2} \cdot \Phi_{2}\right|}
$$

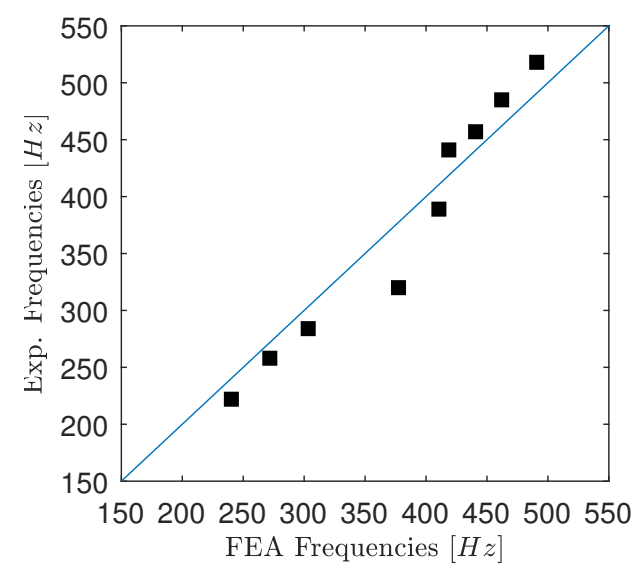

a)

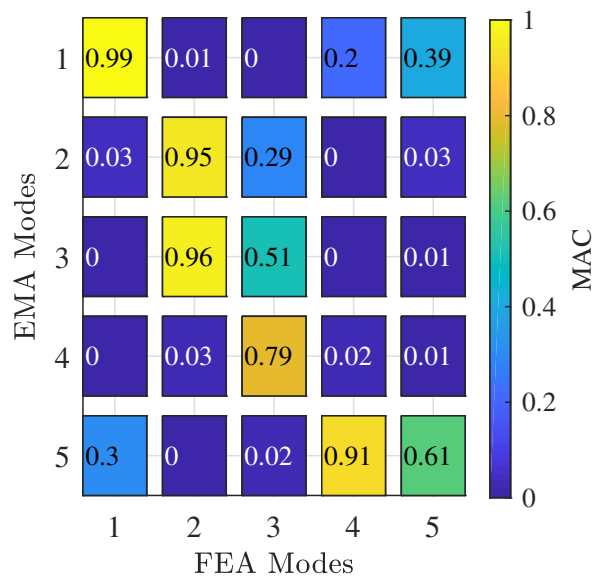

b)

Fig. 9 Experimental and FEA modal analysis comparison in a) resonance frequencies and b) mode shapes using the modal assurance criterion

Four sensors were used, with each recording accelerations in $\mathrm{x}, \mathrm{y}$, and $\mathrm{z}$ axes. Therefore, the compared vectors included 12 degrees of freedom. The mode shapes were calculated by Quadrature Picking, which uses the imaginary part of the frequency response function. It can be seen that the second mode of the FEA calculations matches the second and third mode of the experiment, which means that the model was not capable of identifying all mode shapes properly. As the third mode of the FEA calculations matches the fourth mode in the FEA, the frequency comparison in Fig. 9 a) has to be reconsidered for these modes.

This discrepancy can be explained by the perfectly symmetric FEA model, while the experiment lacks this ideal. Additionally, the free-free configuration was realized by soft rubber bands, which do still have an influence, as well as the sensors' cables. Nevertheless, this analysis was considered matching regarding to the uncertainties not included in the model.

Furthermore, the four sensor positions do not describe the mode shapes entirely, why we can see agreements between modes, e.g. 1st EMA with 5th FEA, which are probably not the same. 


\section{Bio-Based Mass Content, Energy and $\mathrm{CO}_{2}$ Savings}

Table 4 is summarizing the mass contents by materials of the manufactured tailplane and Fig. 10 is visualizing the mass fractions of the materials contained in the respective tailplane version. A total mass of $505 \mathrm{~g}$ was measured, while a $450 \mathrm{~mm}$ section of the reference tailplane weighs $528 \mathrm{~g}$, thus, the masses were almost the same. The new design contains a bio-based mass fraction of $55 \%$.

Also, the eco-efficiency quantification factors of embodied energy in $\mathrm{MJ} \mathrm{kg}^{-1}$ and the carbon footprint in $\mathrm{CO}_{2}-\mathrm{kg} \mathrm{kg}^{-1}$ are listed for primary production of the used materials. Several papers claim different values for embodied energy for used materials [13-16]. In this paper, the authors calculated with values by Ashby [2], as his data ordered well in between the other sources and values for the materials are included, which supports comparability.

Table 4 Mass contents by material of a $450 \mathrm{~mm}$ section of both tailplane versions, and embodied energy and $\mathrm{CO}_{2}$ per material in the primary production process (data basis from [2])

\begin{tabular}{lrc|rrrrr|rrrr}
\multicolumn{4}{c}{ Material } & \multicolumn{4}{c}{ Hybrid Tailplane } & \multicolumn{3}{c}{ Carbon Tailplane } \\
Unit & $\frac{M J}{\mathrm{~kg}}$ & $\mathrm{CO}_{2} \frac{\mathrm{kg}}{\mathrm{kg}}$ & {$[\mathrm{g}]$} & {$[\%]$} & $\frac{M J}{\text { Part }}$ & $\mathrm{CO}_{2} \frac{\mathrm{kg}}{\text { Part }}$ & {$[\mathrm{g}]$} & {$[\%]$} & $\frac{M J}{\text { Part }}$ & $\mathrm{CO}_{2} \frac{\mathrm{kg}}{\text { Part }}$ \\
\hline Carbon Fiber & 400 & 25.2 & 36.7 & 7 & 14.7 & 0.93 & 233.1 & 44 & 93.2 & 5.87 \\
Flax Fiber* & 11 & 0.4 & 247.2 & 49 & 2.7 & 0.10 & 0.0 & 0 & 0.0 & 0.00 \\
Epoxy Resin & 134 & 7.2 & 171.3 & 34 & 23.0 & 1.23 & 125.5 & 24 & 16.8 & 0.90 \\
Balsa Core* & 10 & 0.9 & 31.5 & 6 & 0.3 & 0.03 & 0.0 & 0 & 0.0 & 0.00 \\
Foam Core (PVC) & 59 & 2.5 & 0.0 & 0 & 0.0 & 0.00 & 169.0 & 32 & 10.0 & 0.42 \\
Scotch-Weld & 134 & 7.2 & 18.0 & 4 & 2.4 & 0.13 & 0.0 & 0 & 0.0 & 0.00 \\
\hline Total & & & 504.7 & 100 & 43.1 & 2.40 & 527.6 & 100 & 120.0 & 7.20 \\
* 100\% bio-based materials & & & & & & & & &
\end{tabular}

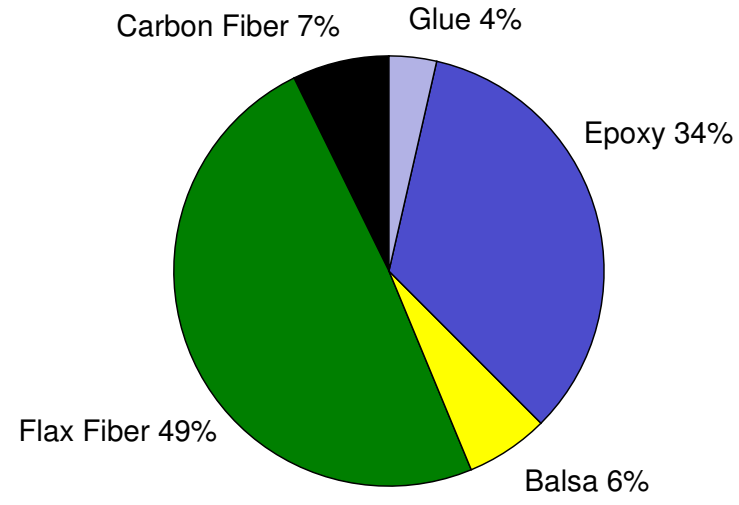

Hybrid Tailplane

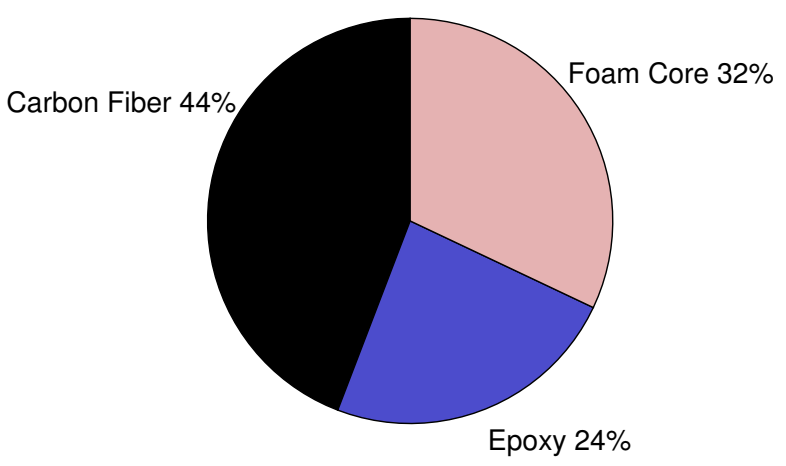

Carbon Tailplane

Fig. 10 Mass fractions of materials in hybrid and carbon tailplane versions by percentage

The potential for saving energy is driven by the use of bio-based fibers, which consume approximately $11 \mathrm{MJ}^{\mathrm{kg}} \mathrm{H}^{-1}$ instead of $400 \mathrm{MJ} \mathrm{kg}^{-1}$ which applies to carbon fibers, both compared in material primary production data from [2]. When these and other data as written in Table 4 are applied to the mass-fractions of both tail planes, a reduction of $76.90 \mathrm{MJ}$ of embodied energy is possible, as well as a reduction of $4.80 \mathrm{~kg}$ of carbon dioxide. This means the materials primary production were reduced by approximately $65 \%$ in comparison to the reference, in terms of embodied energy and carbon footprint.

Certainly, the production process consumes additional energy, which is claimed by [2] with $40 \mathrm{MJ} \mathrm{kg}^{-1}$ for prepreg 
production and with $100-300 \mathrm{MJ} \mathrm{kg}^{-1}$ for autoclave molding. But as both materials were manufactured using prepreg materials in an autoclave molding process, this step does not lead to additional differences and was neglected.

We can also see that the total embodied energy is mainly driven by the carbon fiber in the conventional tailplane, but considering the low energy consumption of flax, the epoxy resin has relevant contribution to the total embodied energy in the new design. The next step, in order to reduce the environmental impact, would be a substitution of the matrix by partly bio-based epoxy. This would lead to further eco-efficiency, according to [17].

Of course, we also have to consider the operational life of the helicopter, as helicopters consume a lot of energy for additional weight. Both versions could not be compared in terms of lightweight conclusively, as the spar design accounts for weight savings and resulting from different span widths, the requirements were not the same. Nevertheless, it can be concluded that a proper design is more important than the material choice in terms of weight, as the tailplane using the weaker material is more lightweight than the conventional design.

In order to find out about lifecycle proportions in energy consumption, especially weight increase vs. energy savings in primary production and recycling, both tailplane sections were compared over the lifecycle phases "primary production," "operational life," and "end of life." Fig. 11 is showing the comparison in terms of energy and $\mathrm{CO}_{2}$ consumption. An energy-weight-penalty of the helicopter of $1.44 \mathrm{MJ} \mathrm{kg}^{-1}$ was calculated from assumptions as in the introduction section and further a $\mathrm{CO}_{2}$ energy penalty of $0.07 \mathrm{~kg} \mathrm{MJ}^{-1}$. The lower weight of the new design results in energy savings in the operational life of $330 \mathrm{MJ}$ and $\mathrm{CO}_{2}$ savings of $22.4 \mathrm{~kg}$.

Regarding the end of life, carbon fiber reinforced materials lack proper reuse or recyclability possibilities, which are matter of investigation in other research, but not state of the art yet [18-[20]. It is assumed that the high bio-based mass content in the new version tail plane supports recyclability, as flax fibers, as a plant material, could rot or be used in biogas energy production. A bio-based matrix would further support recyclability, but was not taken into account in this study. For the end-of-life analysis, we assumed combustion for all energy and $\mathrm{CO}_{2}$ demands respective to the materials mass proportions, values were assessed from [2].

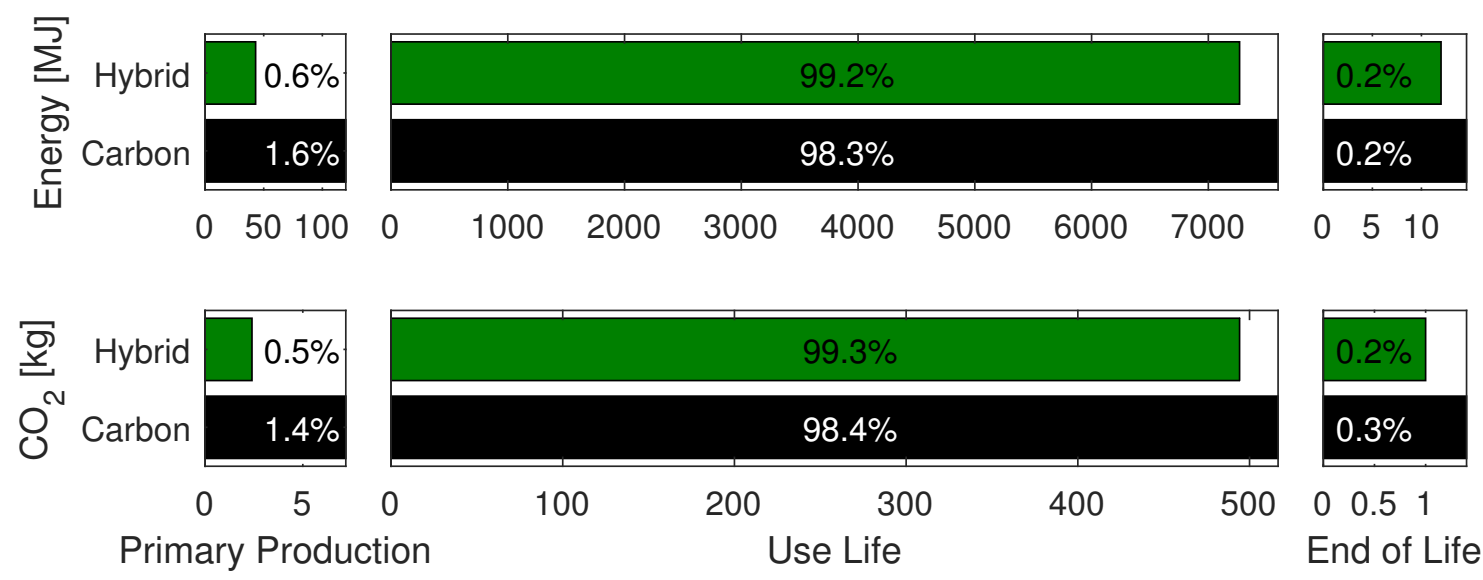

Fig. 11 Energy and $\mathrm{CO}_{2}$ demands of each tailplane section in its life-cycle segments primary production, operational life, and end of life with percentage ratios in proportion to the whole life-cycle

It is clear that especially in helicopter applications, the operational life is the major driver of the overall energy and $\mathrm{CO}_{2}$ consumption, as it is consuming in both versions the most significant ratio. As a conclusion, a weight reduction will typically be superior to energy savings in the primary production and recycling, but if equal weight can be achieved, the natural fiber hybrid design is preferable in terms of eco-efficiency regarding $\mathrm{CO}_{2}$ and energy consumption.

\section{Conclusion}

The goal of this work was to prove applicability of natural fibers in a helicopter tailplane. This endeavor was motivated by the improvement of eco-efficiency in the production process of aerospace parts. A multi-hybrid design using flax, 
carbon, balsa, and epoxy led to promising results. A 55 mass-\% bio-based helicopter tailplane section was successfully built, without drawbacks in weight, strength or stiffness. The lightweight version was achieved by a spar design instead of a core design and is not attributable to the hybrid material.

An experimental modal analysis showed that the damping ratio is two to eight times higher in the hybrid NFRP tailplane than in the CFRP reference, resulting in a potentially beneficial performance regarding tail shake and other vibratory problems. Strength and stiffness requirements were met and experimentally verified, where the FEA model showed good agreement to the test results. The experimental modal analysis showed mode shapes that could not be detected by the FEA model, which were explained by manufacturing and measurement uncertainties in terms of symmetry, boundaries, and measurement influence.

The eco-efficiency was analyzed in terms of materials mass content, respective embodied energy, and $\mathrm{CO}_{2}$ consumption. The assessment of consumed energy in the primary production showed that $76.90 \mathrm{MJ}$ per tailplane could be saved by the new design, which equals 64\% less embodied energy than the carbon design tailplane. Additionally, $4.80 \mathrm{~kg}$ per part of carbon dioxide was reduced, which is again approximately $66 \%$. On the other hand, it was also shown that the operational life requires a lot of energy per mass of the tailplane, which shows that a more lightweight design is typically superior to a bio-based design in the overall eco-efficiency.

\section{Acknowledgments}

The authors thank edm aerotech $\mathrm{GmbH}$ for allowing the comparison between reference and new design as well as for providing the reference tailplane.

The work of Dawid Kobus in his student's term thesis supported this study with design evaluation and pre-design elaboration, the master's thesis of Marc Braun, which contributed to the EMA evaluation, and the master's thesis of Josef Steigenberger which supported the component tests.

The authors also thank Karl-Ludwig Krämer and the team of the LLP machine workshop at TUM for their assistance with manufacturing and experimental setup.

This research was funded under the LUFO-V2 funding program within the project InteReSt (20E1501C) on the basis of a decision by the German Bundestag.

Supported by:

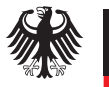

Federal Ministry

for Economic Affairs

and Energy

on the basis of a decision

by the German Bundestag

\section{References}

[1] Madsen, B., and Lilholt, H., "Guidelines for mechanical design with biocomposites: properties, weight and cost," JEC Magazine, Vol. 37, 2007.

[2] Ashby, M., Materials and the Environment: an eco-informed material choice, $2^{\text {nd }}$ ed., Butterworth-Heinemann/Elsevier, 2013.

[3] Rinberg, R., Svidler, R., Klärner, M., Kroll, L., Strohrmann, K., Hajek, M., and Endres, H.-J., “Anwendungspotenzial von naturbasierten hybriden Leichtbaustrukturen in der Luftfahrt," Deutscher Luft- und Raumfahrtkongress 2016, DGLR, Braunschweig, 2016, p. ID: 420092.

[4] Meredith, J., Coles, S. R., Powe, R., Collings, E., Cozien-Cazuc, S., Weager, B., Müssig, J., and Kirwan, K., "On the static and dynamic properties of flax and Cordenka epoxy composites," Composites Science and Technology, Vol. 80, 2013, pp. 31-38. 
[5] Feil, R., Eble, D., and Hajek, M., "Comprehensive Analysis of a Coaxial Ultralight Rotorcraft and Validation with Full-Scale Flight-Test Data," Journal of the American Helicopter Society, Vol. 042004, 2018, pp. 1-12. doi:10.4050/JAHS.63.042004.

[6] Strohrmann, K., and Hajek, M., "Bilinear approach to tensile properties of flax composites in finite element analyses," J Mater Sci, Vol. 54(2), 2018. doi:10.1007/s10853-018-2912-1.

[7] Mahboob, Z., El Sawi, I., Zdero, R., Fawaz, Z. and Bougherara H., "Tensile and compressive damaged response in Flax fibre reinforced epoxy composites," Composites: Part A, Vol. 92, 2017, pp. 118-13.

[8] Mahboob, Z., Chemisky, Y., Meraghni, F. and Bougherara, H., "Mesoscale modelling of tensile response and damage evolution in natural fi bre reinforced laminates," Composites Part B, Vol. 119, 2017, pp. 168-183.

[9] Rueppel, M., Rion, J., Dransfeld, C., and Masania, K., "Damping of carbon fiber and flax fiber reinforced angle ply polymers," 2016.

[10] Assarar, M., Zouari, W., Sabhi, H., Ayad, R., and Berthelot, J. M., "Evaluation of the damping of hybrid carbon-flax reinforced composites," Composite Structures, 2015. doi:10.1016/j.compstruct.2015.05.016.

[11] Le Guen, M. J., Newman, R. H., Fernyhough, A., and Staiger, M. P., "Tailoring the vibration damping behaviour of flax fibre-reinforced epoxy composite laminates via polyol additions," Composites Part A: Applied Science and Manufacturing, 2014. doi:10.1016/j.compositesa.2014.08.018.

[12] Gelfuso, M. V., Thomazini, D., César, J., De Souza, S., and Juliano De Lima Junior, J., "Vibrational Analysis of Coconut Fiber-PP Composites," Materials Research, Vol. 17, No. 2, 2014, pp. 367-372. doi:10.1590/S1516-14392013005000200.

[13] Koezjakov, A., Urge-Vorsatz, D., Crijns-Graus, W., and van den Broek, M., "The relationship between operational energy demand and embodied energy in Dutch residential buildings," Energy and Buildings, Vol. 165, 2018, pp. $233-245$. doi:10.1016/j.enbuild.2018.01.036.

[14] Dissanayake, N. P., Summerscales, J., Grove, S. M., and Singh, M. M., "Energy use in the production of flax fiber for the reinforcement of composites," Journal of Natural Fibers, Vol. 6, No. 4, 2009, pp. 331-346. doi:10.1080/15440470903345784.

[15] Suzuki, T., and Takahashi, J., "Prediction of Energy Intensity of Carbon Fiber Reinforced Plastics for Mass-Produced Passenger Cars," 9th Japan International SAMPE Symposium, 2005.

[16] Song, Y. S., Youn, J. R., and Gutowski, T. G., "Life cycle energy analysis of fiber-reinforced composites," Composites Part A: Applied Science and Manufacturing, Vol. 40, No. 8, 2009, pp. 1257-1265. doi:10.1016/j.compositesa.2009.05.020.

[17] Rudin, A., and Choi, P., "Biopolymers," The Elements of Polymer Science \& Engineering, 2013, Chap. 13, pp. 521-535. doi:10.1016/B978-0-12-382178-2.00013-4.

[18] Howarth, J., Mareddy, S. S. R., and Mativenga, P. T., "Energy intensity and environmental analysis of mechanical recycling of carbon fibre composite," Journal of Cleaner Production, Vol. 81, 2014, pp. 46-50. doi:10.1016/j.jclepro.2014.06.023.

[19] Baz, S., Ausheyks, L., Reichert, O., Dinkelmann, A., Finckh, H., Hehl, J., Poeppel, A., and Gresser, G. T., "Recycling of long carbon fibers, part I: Development of a high aligned RCF-sliver for a binder tape manufacturing process," ECCM18 - 18th European Conference on Composite Materials, Athens, 2018, pp. 24-28.

[20] Schueppel, D., Stockschlaeder, J. and von Reden, T., "End-of-life CFRP as raw material in steel and of calcium carbide production," ECCM18 - 18th European Conference on Composite Materials, Athens, 2018, pp. 24-28. 